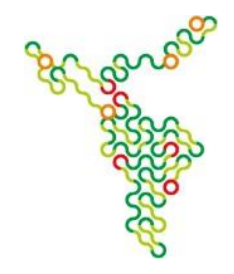

\title{
ALGUNS CONCEITOS E CONTRIBUIÇÕES DE PIERRE BOURDIEU NO CAMPO EDUCACIONAL
}

\author{
Rita Schane ${ }^{1}$ \\ Andrea Garcia Furtado ${ }^{2}$ \\ Roberta Ravaglio Gagno ${ }^{3}$
}

\begin{abstract}
Resumo: Este artigo tem por objetivo refletir os conceitos de habitus, campo, capital, capital cultural e violência simbólica a luz dos escritos de Pierre Bourdieu, no campo educacional. O conceito de habitus discorre sobre a capacidade dos sentimentos, dos pensamentos e das ações dos indivíduos quanto à incorporação de determinada estrutura social. O campo representa um espaço no qual os confrontos legitimam as representações, considerando o poder simbólico como aquele que classifica os símbolos de acordo com a existência ou ausência de um código de valores, já o capital representa o acúmulo de forças que o indivíduo pode alcançar no campo. O artigo busca compreender como os indivíduos incorporam a estrutura social, legitimando-a e reproduzindo-a, por meio da instituição escolar, mais precisamente a partir da violência simbólica.
\end{abstract}

Palavras-chave: Habitus. Campo. Capital. Capital Cultural. Violência Simbólica

\section{SOME CONCEPTS AND CONTRIBUTIONS OF PIERRE BOURDIEU IN THE EDUCATIONAL FIELD}

\begin{abstract}
This article aims to reflect the concepts of habitus, field, capital, cultural capital and symbolic violence in the light of Pierre Bourdieu's written texts in the educational field. The concept of habitus discusses the capacity of the individuals' feelings, thoughts and actions regarding the incorporation of a given social structure. The field represents a space in which the confrontations legitimize the representations, considering the symbolic power as the one that classifies the symbols according to the existence or the absence of a code of values, whereas the capital represents the accumulation of forces that the individual can reach in the field. The article searches to understand how individuals incorporate the social structure, legitimizing and reproducing it through the school institution, more precisely from the symbolic violence.
\end{abstract}

Keywords: Habitus. Field. Capital. Cultural Capital. Symbolic Violence.

\footnotetext{
${ }^{1}$ Mestre em Educação. Professora da FARESC. Curitiba - Paraná - Brasil.

${ }^{2}$ Doutoranda em Educação. Professora da FARESC. Curitiba - Paraná - Brasil.

${ }^{3}$ Doutora em Educação. Professora da UNESPAR. Curitiba - Paraná - Brasil.
} 


\section{Universidade do Extremo Sul Catarinense \\ Revista Ibero-Americana de Humanidades, Ciências e \\ Educação \\ Unesc Produção e democratização do conhecimento na lbero-América}

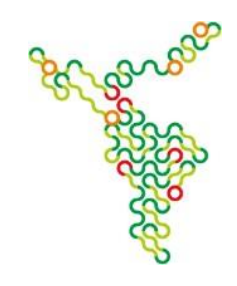

\section{INTRODUÇÃO}

O sociólogo Pierre Bourdieu nasceu em 01 de agosto de 1930, na cidade de Denguin, na França. Ele foi esponsável por uma sua vasta produção intelectual, recebendo o título de Doutor honoris causa em três importantes instituições da Europa, na Universidade Livre de Berlim, em 1989; na Universidade Johann Wolfgang Goethe, em 1996; e, na Universidade de Atenas, no mesmo ano. Pierre Bourdieu faleceu no dia 23 de janeiro de 2002, na cidade de Paris.

Bourdieu era estruturalista e explicou o estruturalismo como um processo pelo qual o homem deixa a sua estrutura inicial para passar à uma nova estrutura, a cultural. Inicialmente, faz isso para satisfazer suas necessidades, utilizando símbolos, produzindo alianças, ou seja, passando a estabelecer relações sociais.

Para explicar esse conceito, Bourdieu se apropriou dos estudos realizados por Marx sobre o capitalismo, mais especificamente, sobre a luta de classes. Desse modo, aproveitou o conceito de estrutura inata, que para Marx se consolidava no princípio de que esta se tratava de uma estrutura que já estaria dada naturalmente, inserindo nesse conceito o conflito de classes, pois tanto para Marx, quanto para Weber, seria impossível existir uma sociedade sem conflitos.

Para além desse conceito, Bourdieu afirmou que as estruturas não são inatas, elas são adquiridas a partir dos embates que existem entre as pessoas, ou seja, de dinâmicas de força que naturalmente nascem das relações estabelecidas por elas, e essas relações fundamentam o social, "o homem é ao mesmo tempo, produto e produtor da sua história." (Ortiz, 1983, p.9).

Estudioso das práticas dos indivíduos, Bourdieu, para entender melhor o social, buscou compreender o real e o social, ou seja, o objetivo e o subjetivo. Para compreender o indivíduo e como ele agia e reagia às estruturas reais e sociais, identificou que é necessário recuperar as estruturas que interferem nas suas escolhas pessoais, nesse sentido, Ortiz (1983, p.15) destaca que "as ações são concretamente realizadas pelos indivíduos, mas as chances de efetivá-las se encontram objetivamente estruturadas no interior da sociedade global". 


\section{Universidade do Extremo Sul Catarinense \\ Revista Ibero-Americana de Humanidades, Ciências e \\ Educação \\ UnesC Produção e democratização do conhecimento na lbero-América}

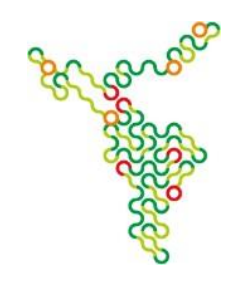

Portanto, as estruturas implicam em uma ação que consolida a prática do indivíduo que as internalizou, fazendo parte do mundo no qual o indivíduo está inserido. Um exemplo disso, seria a família, o primeiro local que o informa sobre as verdades, a ética, a estética, ou seja, esse espaço determina um conjunto de percepções, das quais esse indivíduo se apropria, inicialmente.

A percepção primeira do mundo social, longe de ser um reflexo mecânico é sempre um ato de conhecimento que faz intervir princípios de construção exteriores ao objeto construído, apreendido em seu imediatismo, mas que por ser destituído do controle de tais princípios de sua relação com a ordem real que eles produzem, é um ato de desconhecimento, implicando a forma mais absoluta de reconhecimento da ordem social. (BOURDIEU, 2007, p.438).

Vale salientar que o conhecimento de toda essa estrutura por parte do ser humano se constitui por atos lógicos, pois o que move o ser humano é a lógica da lógica. Mas, essa incorporação se faz por um conjunto de esquemas de percepção e apreciação que auxiliam o indivíduo em tal processo, o instrumentalizando quanto aos valores que o condicionam para a sua posição social e suas propriedades, constituindo assim o seu valor, no seu tempo e no seu espaço.

[...] aprender estruturas e mecanismos que, ainda que por razões diferentes, escapam tanto ao olhar nativo, quanto ao olhar estrangeiro, tais como os princípios de construção de espaço social ou mecanismos de reprodução desse espaço e que ele acha que pode representar e um modelo que tem a pretensão de validade universal. Ele pode indicar as diferenças reais que separam tanto as estruturas quanto as disposições (os habitus) e cujo princípio é preciso procurar, mas não na singularidade das naturezas ou das "almas" -, mas nas particularidades de histórias coletivas diferentes." (PASSERON, 1995, p.15).

Quando se discute o indivíduo, automaticamente se discutem seus valores, sua posição social, a classe a que pertence, ou seja, ele passa a ser categorizado. O seu habitus se compõe justamente dessa transmissão de valores, da sua história, aquela que the foi inculcada, ensinada a partir das às condições de socialização dadas no espaço e no tempo em que o indivíduo está inserido.

"o habitus tende, portanto, a conformar e orientar a ação, mas na medida em que é produto das relações sociais ele tende a assegurar a reprodução dessas mesmas relações objetivas que o engendraram. A interiorização, pelos atores, dos 


\section{Universidade do Extremo Sul Catarinense \\ Revista Ibero-Americana de Humanidades, Ciências e \\ Educação \\ UnesC Produção e democratização do conhecimento na lbero-América}

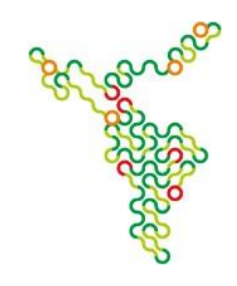

valores, normas e princípios sociais assegura, dessa forma, a adequação entre as ações do sujeito e a realidade objetiva da sociedade como um todo." (ORTIZ, 1983, p.15).

Desse modo, o habitus refere-se ao social e ao individual; a um indivíduo, a uma classe ou a um grupo específico, podendo ser internalizado de modo objetivo, porém de forma subjetiva, o que quer dizer que cada pessoa, independentemente de sua classe, vai internalizar individualmente, pois cada indivíduo é único e mesmo que socializado na mesma classe social que outro, por exemplo, pode ter tendências e hábitos semelhantes, não necessariamente iguais. Conclui-se que as condições de socialização são únicas.

Por isso, pode-se afirmar que o indivíduo teria uma matriz de ação e de percepção que o orientaria quanto às suas possibilidades, e para Bourdieu, esse seria um habitus de classe, uma espécie de manual que indicaria como posicionarse dentro da sua estrutura, do seu habitus, alterável de acordo com o tempo e o espaço, denominando-se campo.

O campo designa atividade humana, espaço nos quais se desenrolam lutas pela detenção do poder simbólico, que produz e confirma significados. Essas lutas consagram valores que se tornam aceitáveis pelo senso comum. Por exemplo, no campo da arte, a luta simbólica decide o que é erudito ou popular, de bom ou de mau gosto.

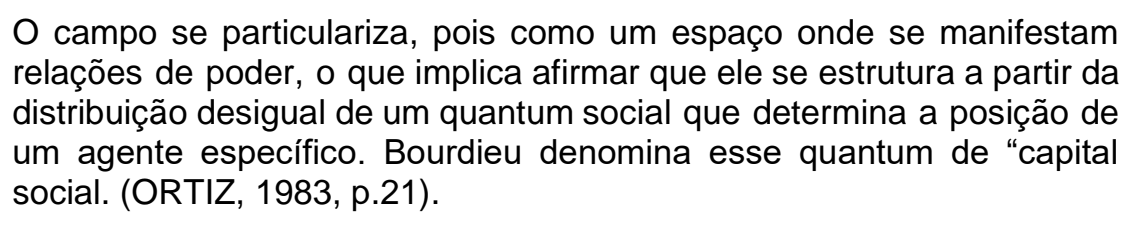

O campo é um espaço de disputa e delimita o habitus, sendo então percebido como um recurso metodológico para entender o mundo e as relações de força e poder que estão presentes em si mesmo. O campo determina o capital social, e no caso do campo científico, traduz-se em competência científica, possibilitando aos dominantes que a detém, maior prestígio e legitimidade enquanto sua posição dominante. "Ao pólo dominante correspondem às práticas 


\title{
Universidade do Extremo Sul Catarinense \\ Revista Ibero-Americana de Humanidades, Ciências e \\ Educação \\ UneSC Produção e democratização do conhecimento na lbero-América
}

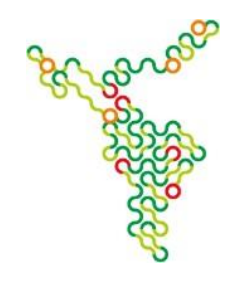

de uma ortodoxia que pretende conservar intacto o capital social acumulado, ao pólo dominado, as práticas heterodoxas que tendem a desacreditar os detentores reais de um capital legítimo." (ORTIZ, 1983, p.22).

Cabe destacar que os campos representam espaços estruturados de posições. As propriedades dessas posições dependem do lugar que eles ocupam no espaço. Tais posições podem ser analisadas independentemente das características dos indivíduos. Os campos sofrem influências de outros campos (econômico, social, cultural,....). Cada campo tem as suas próprias leis, porém existem leis que regem a todos os campos e que estão presentes em todas as relações existentes no interior deles, ou seja, quanto mais forte for o campo, mais influência ele exercerá sobre os demais campos. Isso quer dizer que sempre haverá uma luta específica entre os ideais daquele que está sendo inserido em um novo campo e os ideais que já foram internalizadas por ele, os quais os auxiliam na defesa dos seus próprios interesses.

\begin{abstract}
A partir do momento em que não há luta, quer dizer resistência dos dominados, há monopólio dos dominados e a história pára. Os dominantes em todos os campos, vêem a sua dominação como o fim da história - no duplo sentido de termo e de meta, que não tem para além de si próprio e se eterniza." (BOURDIEU, 1983, p.176). Portanto, o campo determina a posição que o indivíduo ocupa no tempo e no espaço e também destaca que as "condições econômicas e sociais de aquisição da competência legítima e da constituição do mercado onde se estabelece e se impõe esta definição do que é legítimo e ilegítimo." (BOURDIEU, 1998, p.30).
\end{abstract}

Ou seja, as relações de poder definem as classes sociais. Cada campo define os objetos de disputa e os seus interesses. Os indivíduos devem ser dotados de um habitus próprio capaz de conhecer e reconhecer as leis próprias daquele campo, identificando as relações de força e a importância da distribuição do capital, seja ele cultural, econômico ou social.

A estrutura de um campo pode ser alterada a partir de condições específicas atuais do tempo e do espaço nos quais está inserido. As lutas travadas no seu interior vão determinar o que é permanente ou não nesse campo, até porque as lutas buscam o monopólio, a conservação ou a manutenção da 


\title{
Universidade do Extremo Sul Catarinense \\ Revista lbero-Americana de Humanidades, Ciências e \\ Educação \\ Unesc Produção e democratização do conhecimento na lbero-América
}

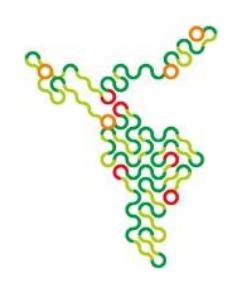

estrutura e da distribuição do capital.

\begin{abstract}
As oposições aparentemente mais formais dessa mitologia social devem sempre sua eficácia ideológica ao fato de que elas remetem mais ou menos discretamente às oposições mais fundamentais da ordem social: a oposição que inscrita na divisão do trabalho, se estabelece ente dominantes e dominados, por um lado, por outro, a oposição que, baseada na divisão de trabalho de dominação, opõe no âmago da classe dominante, dois princípio de dominação, dois poderes, dominante e dominado, temporal e espiritual, material e intelectual, etc." (BOURDIEU, 2007,p.436).
\end{abstract}

A partir dos habitus que diferenciam os campos, pode-se discutir o conceito de capital. Bourdieu o categorizou em capital econômico, social e cultural. Ambos designam "essa natureza cultivada, cuja gênese social tornou-se invisível para aqueles que a percebem por meio das categorias mentais que são o produto dela" (Wacquant, 2000, p. 120), ou seja, essa distinção entre os indivíduos a partir das suas origens passa a ficar invisível a olho nu, ou seja, naturalizada.

Com isso, as lutas existentes nos e entre os campos pautam-se em dois grandes movimentos: daqueles que monopolizam o capital específico e detém as estratégias de conservação da sociedade tal como está posta, e daqueles que possuem menos capital, tendenciando para a subversão da ordem estabelecida e da distribuição do capital.

Os indivíduos se posicionam nos campos de acordo com o capital acumulado - que pode ser social, cultural, econômico e simbólico. Por exemplo, o capital social corresponde à rede de relações e interações que cada um constrói, com os benefícios ou malefícios que elas podem gerar entre os grupos humanos. $\mathrm{Na}$ educação se acumula, portanto, o capital cultural, na forma de conhecimentos apreendidos, livros, diplomas.

Hoje, gostaria de lembrar os mecanismos extremamente complexos pelos quais a instituição escolar contribui (insisto nessa palavra) para reproduzir a distribuição do capital cultural e, assim a estrutura do espaço social. As duas dimensões fundamentais desse espaço, as quais lembrei ontem, correspondem dois conjuntos de mecanismos de reprodução diferentes - cuja combinação define o modo de reprodução , que fazem com que o capital puxe o capital e com que a estrutura social tenda a perpetuar-se (não sem sofrer deformações mais ou menos importantes). A reprodução da estrutura de distribuição do capital cultural se dá na relação entre as estratégias das famílias e a lógica especifica da instituição escolar." (BOURDIEU, 1994, p.35). 


\section{Universidade do Extremo Sul Catarinense \\ Revista Ibero-Americana de Humanidades, Ciências e \\ Educação \\ UnesC Produção e democratização do conhecimento na lbero-América}

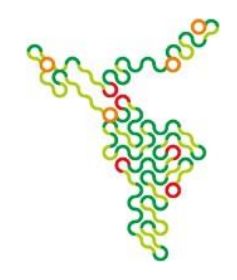

Cabe destacar que Bourdieu identificou a escola como um espaço de reprodução das estruturas sociais e de transferência de capitais de uma geração para outra. Também ressaltou que por meio dela, o legado econômico da família transforma-se em capital cultural e que isso impacta diretamente no desempenho dos alunos em sala de aula, tendo em vista que eles, normalmente, são julgados pelo campo do qual são provenientes tanto pela quantidade, quanto pela qualidade do conhecimento que já trazem de casa, além das suas heranças e dos seus habitus.

Os próprios estudantes mais pobres acabam percebendo a trajetória dos melhores alunos como algo resultante de um esforço recompensado e que possivelmente não conseguirão atingir. Isso comprovaria os mecanismos de perpetuação das desigualdades sociais, pois o fracasso escolar leva muitos alunos e as suas famílias a investirem menos esforços no aprendizado formal, desenhando um círculo que se autoalimenta e que perpetua a sociedade tal como está posta.

"O sistema de ensino, cuja ação se amplia e se intensifica no decorrer do século XIX, sem dúvida contribui diretamente quer para a desvalorização dos modos de expressão populares, relegados ao estado de "jargão" e de "algavaria" (como dizem as anotações marginais dos mestres), quer para a imposição do reconhecimento da língua legítima." (BOURDIEU, 1998, p.36).

Nessa perspectiva, a ideia do capital cultural está intimamente ligada à origem social do indivíduo. O volume de capital cultural total adquirido em suas estruturas passa a definir o seu lugar nesse campo. Nesse caso, o capital cultural dos estudantes não é aquele do qual se apropriará na escola, mas sim, aquele já adquirido e que passa a posicioná-lo no ambiente escolar. Ou seja, a cultura geral e aceita como "melhor", é a cultura da classe dominante.

A escola passa então a valorizá-la, deixando de lado a sua função transformadora, reproduzindo e reforçando as desigualdades sociais. Quando a criança chega à escola em busca da educação formal, ela é recebida por um campo marcado pelo caráter de classe, pela segmentação, em todos os sentidos, 


\section{Universidade do Extremo Sul Catarinense \\ Revista Ibero-Americana de Humanidades, Ciências e \\ Educação \\ UneSC Produção e democratização do conhecimento na lbero-América}

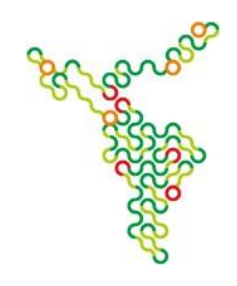

desde a sua organização pedagógica até a forma como avalia os estudantes. Mas tudo isso ocorre de forma silenciosa, pela qual opera a violência simbólica.

O traço próprio da dominação simbólica reside precisamente no fato de que ela supõe, da parte de quem a sofre, uma atitude que desafia a alternativa simbólica entre a liberdade e a correção: as "escolhas" do habitus (aquela, por exemplo, que consiste em corrigir o $r$ em presença de locutores legítimos) são realizadas, sem consciência nem coerção, por força das disposições constituídas igualmente fora da consciência e da coerção, apesar de serem indiscutivelmente o produto de determinismos sociais (BOURDIEU, 1998, p.36).

Para concluir, seria essa uma das formas, destacadas por Bourdieu, pela qual a escola faz uso da violência simbólica, reproduzindo assim, as desigualdades sociais. Destaca-se também que, ao se referir ao controle de um campo sobre outro, utilizou o conceito de violência simbólica, como aquela legitimadora da dominação e colocada em prática por meio de habitus. Isso explicaria por que é tão difícil alterar certos padrões sociais: o poder exercido em campos como a linguagem é mais eficiente e sutil do que o uso da força propriamente dita.

\section{Referências}

BOURDIEU, P. A Distinção: crítica social do julgamento. Porto Alegre, Zouk, 2007. BOURDIEU, P. A Economia das trocas linguísticas. São Paulo: EDUSP, 1998.

BOURDIEU, P. Questões de sociologia. Rio de Janeiro: Marco Zero, 1983. BOURDIEU, P. Razões Práticas. Campinas: Papirus, 1994.

ORTIZ, R. Pierre Bourdieu. São Paulo: Ática, 1983.

PASSERON, J. C. O raciocínio sociológico: o espaço não popperiano do raciocínio natural.

Petrópolis: Vozes, 1995.

WACQUANT, L. Corpo e alma: notas etnográficas de um aprendiz de boxe. Rio de Janeiro: Relume Dumará, 2000. 